Check for updates

Cite this: RSC Adv., 2022, 12, 3445

Received 21st November 2021 Accepted 18 th January 2022

DOI: $10.1039 / \mathrm{d} 1 \mathrm{ra0} 8526 \mathrm{c}$

rsc.li/rsc-advances

\section{Voltammetric determination of Salmonella typhimurium in minced beef meat using a chip- based imprinted sensor}

\author{
Shaimaa A. Khalid, $\dagger^{\text {ac }}$ Rabeay Y. A. Hassan, (D) $\dagger^{\text {ab }}$ Rasha Mohamed El Nashar ${ }^{\star d}$ \\ and Ibrahim M. El-Sherbiny (iD *a
}

\begin{abstract}
Early detection of pathogens is necessary for food quality monitoring, and increasing the survival rate of individuals. Conventional microbiological methods used to identify microorganisms, starting from bacterial culture and ending with advanced PCR gene identification, are time-consuming, laborious and expensive. Thus, in this study, a bacterial imprinted polymer (BIP)-based biosensor was designed and fabricated for rapid and selective detection of Salmonella typhimurium. Bio-recognition sites were made by creating template-shaped cavities in the electro-polymerized polydopamine matrices on a gold screen-printed electrode. The overall changes of the sensor, during the imprinting process, have been investigated with cyclic voltammetry, atomic force microscopy and scanning electron microscopy. The assay optimization and validation were accomplished, hence the highest sensitivity and selectivity towards S. typhimurium were achieved. As a result, a very low limit of detection of $47 \mathrm{CFU} \mathrm{ml}^{-1}$, and a limit of quantification of $142 \mathrm{CFU} \mathrm{ml^{-1 }}$ were achieved using the newly-developed biosensor. No interference signals were detected when the S. typhimurium was tested in a mixed culture with other non-targeted pathogens such as Staphylococcus aureus, Listeria monocytogenes and Campylobacter jejuni. Eventually, the biosensor was applied to minced beef meat samples offering not only fast detection but also direct determination with no bacterial enrichment steps.
\end{abstract}

\section{Introduction}

In terms of spreading bacterial infection, exposure to food contaminated with pathogenic microorganisms is the main reason behind microbial infections. Viruses, bacteria and fungi are the most common causes of food poisoning. ${ }^{1}$ Salmonella, a Gram-negative bacteria, was found to cause a very common foodborne illness and that is why the Center for Disease Control and Prevention has classified Salmonella as a B-class bioterrorism agent. ${ }^{2,3}$ Several clinical symptoms including vomiting, fever, nausea, diarrhea, and abdominal pain are caused by Salmonella infection. ${ }^{\mathbf{4 , 5}}$

From the diagnostic point of view, Salmonella detection in food is necessary to ensure food safety and high quality. ${ }^{6}$ However, classical microbiological detection protocols, namely,

\footnotetext{
${ }^{a}$ Nanomedicine Research Labs, Center for Materials Science, Zewail City of Science and Technology, 6th October City, 12578 Giza, Egypt. E-mail: ielsherbiny@zewailcity.edu. eg

${ }^{b}$ Applied Organic Chemistry Department, National Research Centre (NRC), Dokki, 12622, Giza, Egypt

${ }^{c}$ Food Hygiene Department, Animal Health Research Institute (AHRI), Agricultural Research Center (ARC), Egypt

${ }^{d}$ Chemistry Department, Faculty of Science, Cairo University, Giza, 12613, Egypt.

E-mail: rashaelnashar@gmail.com

$\dagger$ Equal author contribution.
}

microbial isolation in culture media requires long steps of preenrichment and selective enrichment. ${ }^{7-10}$ Consequently, various molecular techniques such as ELISA and PCR procedures were introduced to provide higher sensitivity and selectivity in comparison with conventional microbiological isolation methods. ${ }^{11}$ However, those techniques are still expensive and time consuming methodologies with a reported limit of detection for Salmonella of $10^{4}$ to $10^{5} \mathrm{CFU} \mathrm{ml}^{-1}$ and $10^{4} \mathrm{CFU} \mathrm{ml}{ }^{-1}$ for ELISA, ${ }^{12}$ and PCR, ${ }^{13}$ respectively.

Biosensors have recently grasped attention as analytical platforms that can be tailored and developed in different ways so as to provide a fast and early diagnostic tool for detection of different analytes including pathogens and their toxins. ${ }^{\mathbf{1 4 - 1 8}}$

Simultaneous detection of E. coli $\mathrm{O}$ 157:H7, Campylobacter and Salmonella has been conducted by immobilizing a mixture of antibodies against the three target pathogenic strains. ${ }^{19}$ Another electrochemical immunosensor was reported for the fast detection of $S$. pullorum using gold nanoparticles (GNPs) modified screen printed electrodes, where a LOD of $3 \times 10^{3} \mathrm{CFU}$ $\mathrm{ml}^{-1}$ was achieved. ${ }^{20}$ Impedimetric immunosensor for the detection of $S$. typhimurium in water and juice samples was reported with high sensitivity. ${ }^{21,22}$

Molecular imprinting technology (MIT), which is found to have a significant role in improving the selectivity of electrochemical sensors, was exploited in pathogenic detection. ${ }^{\mathbf{1 4 , 2 3 , 2 4}}$ 
Besides, MIT was considered as a very efficient technique for the separation and analysis of specific compounds in complex environments. In addition, whole cells imprinting as a template has been reported for many applications including microbial fuel cells, ${ }^{25}$ specific cell capture, cell-sorting and separation ${ }^{26}$ as well as microbial detection. ${ }^{27,28}$

Since the $S$. typhimurium detection in food turned to be an obligation by food safety authorities worldwide, the main objective of the current study is to construct a novel electrochemical biosensor for selective, sensitive and fast detection of $S$. typhimurium in complex matrices such as meat and biological samples. In this concern, bacteria-imprinted recognition sites were created on the surface of an electro-polymerized poly(dopamine), in situ formed on the sensor surfaces. This design possesses high physical and electrochemical stabilities that could be exploited directly without prior sample preparation such as bacterial isolation or molecular identification.

\section{Materials and methods}

\subsection{Reagents, chemicals and biological materials}

2.1.1. Bacterial strains. S. typhimurium (NCTC12023), Staphylococcus aureus (NCTC10788), Listeria monocytogenes (NCTC13372) and Campylobacter jejuni (NCTC11168) were obtained from Animal Health Research Institute, Cairo, Egypt. The culture medium, trypticase soya broth, potassium chloride, potassium ferricyanide, Triton X-100, ammonium acetate, and dopamine hydrochloride were obtained from Sigma-Aldrich (St Louis, MO). Phosphate buffer solutions (PBS, $0.1 \mathrm{M}$ ) were prepared using $\mathrm{H}_{3} \mathrm{PO}_{4}, \mathrm{NaH}_{2} \mathrm{PO}_{4}$ or $\mathrm{NaHPO}_{4}$ and adjusted to the required $\mathrm{pH}$ with $\mathrm{NaOH}$ or $\mathrm{HCl}$ solutions. $0.1 \mathrm{M}$ of ammonium acetate buffer ( $\mathrm{pH}$ 5.5) was prepared by dissolving $7.7 \mathrm{~g}$ ammonium acetate in one liter of MQ-water, and the pH 5.5 was adjusted using acetic acid. Gold screen printed electrodes (3 electrode-chip from Drop Sense) were used for the MIP formation and electrochemical measurements. The electrochemical experiments were conducted using computer controlled-Gamry Potentiostat/Galvanostat/ZRA G750 system.

\subsection{Salmonella culture preparation}

Overnight cultures of bacterial strains were performed in trypticase soya broth at $37{ }^{\circ} \mathrm{C}$, and then the cell pellets were collected by centrifugation (3200 rpm, for $10 \mathrm{~min})$. The cells were then re-dispersion in PBS after discarding the supernatant of the overnight culture. Any remaining metabolites were removed by repeating this washing step for 3 consecutive times.

For the determination of the number of colony-forming units per milliliter (CFU ml ${ }^{-1}$ ), the test cultures were grown on trypticase soya broth at $37^{\circ} \mathrm{C}$ for $24 \mathrm{~h}$ followed by serial $1: 10$ dilutions for bacterial culture with PBS. Finally, $0.1 \mathrm{ml}$ of the prepared culture was extended on nutrient agar plates and incubated at $37^{\circ} \mathrm{C}$ for $24 \mathrm{~h}$.

\subsection{Fabrication and characterization of the BIP biosensor}

Polydopamine coating were electro-polymerized on a clean $\mathrm{Au}-$ screen printed electrode. Typically, a mixture of $S$. typhimurium suspension $\left(1 \times 10^{7} \mathrm{CFU} \mathrm{ml}^{-1}\right)$ and dopamine (5 mg ml${ }^{-1}$ ) in ammonium acetate buffer ( $\mathrm{pH}$ 5.5) was electropolymerized at different numbers of cyclic voltammetric sweeps in the potential range from -0.4 to $0.6 \mathrm{~V}$ at variable scan rates in the presence of bacteria imprinted polymers (BIP) and in the absence of $S$. typhimurium. The bacterial particles were removed by exposing the BIP matrix to $1 \%$ Triton followed by washing with PBS. Electrochemical responses of BIP and NIP were recorded before and after the washing procedure. Cyclic voltammetric analysis was used for the electrochemical characterization of BIP preparations (Fig. 1). The morphological characterizations were conducted using atomic force microscopy (AFM) with AutoProbe CP-Research Head (Thermomicroscope, Sunnyvale, California, USA) and field emission-scanning electron microscope, FE-SEM (Quanta FEG250, Czech). ${ }^{24}$

\subsection{Food sample preparation and inoculation}

Freshly ground beef meat was purchased from a local grocery store (Giza, Egypt) and transported immediately to the laboratory in an ice box. The meat samples were cut off into small pieces (10 gram per each) and sterilized using UV radiation. Then, each piece was transferred to a sterile Petri dish containing $100 \mu \mathrm{l}$ of $S$. typhimurium suspension $\left(10^{2}\right.$ to $\left.10^{4} \mathrm{CFU} \mathrm{ml}^{-1}\right)$. Afterwards, $90 \mathrm{ml}$ of sterile PBS was added and mixed using a stomacher machine (Seward stomacher BA 7021, England) at $200 \mathrm{rpm}$ for two min. Noninfected meat sample (i.e. meat sample without inoculation with $S$. typhimurium was used as a negative control). As a reference method, plate counting was used to determine the concentration of bacteria in ground beef by inoculation of the sample on nutrient agar Petri dishes and enumeration after $24 \mathrm{~h}$ at $37{ }^{\circ} \mathrm{C}$. All the prepared samples were directly used in the electrochemical analysis for the detection of the targeted organisms in food samples. Counting the CFU $\mathrm{ml}^{-1}$ of $S$. typhimurium was occurred by bacterial count on the Xylose Lysine Deoxycholat (XLD) agar plat.

\subsection{Statistics and data analysis}

All data are presented as mean \pm SD from at least three individual experiments. Statistical significance was determined by statistical hypothesis testing where the significance of the values was assumed as $p<0.05$. From the standard calibration curves, the limit of detection (LOD) and the limit of quantification (LOQ) were calculated. The reproducibility of the sensor responses was represented by the relative standard deviation (RSD). Statistical analysis was performed using Origin-Lab software which was used for drawing all presented figures.

\section{Results and discussion}

\subsection{Bacterial imprinted polymer (BIP) formation}

3.1.1. A brief on the main concept of this sensor's design. Electrochemical imprinting of individual cells of $S$. typhimurium will be carried out through the formation of a homogenous polymeric layer on the surface of electrode chip. Accordingly, removal of the imprinted bacterial cells from this polymeric matrix will create specific binding sites (unique $S$. typhimurium 


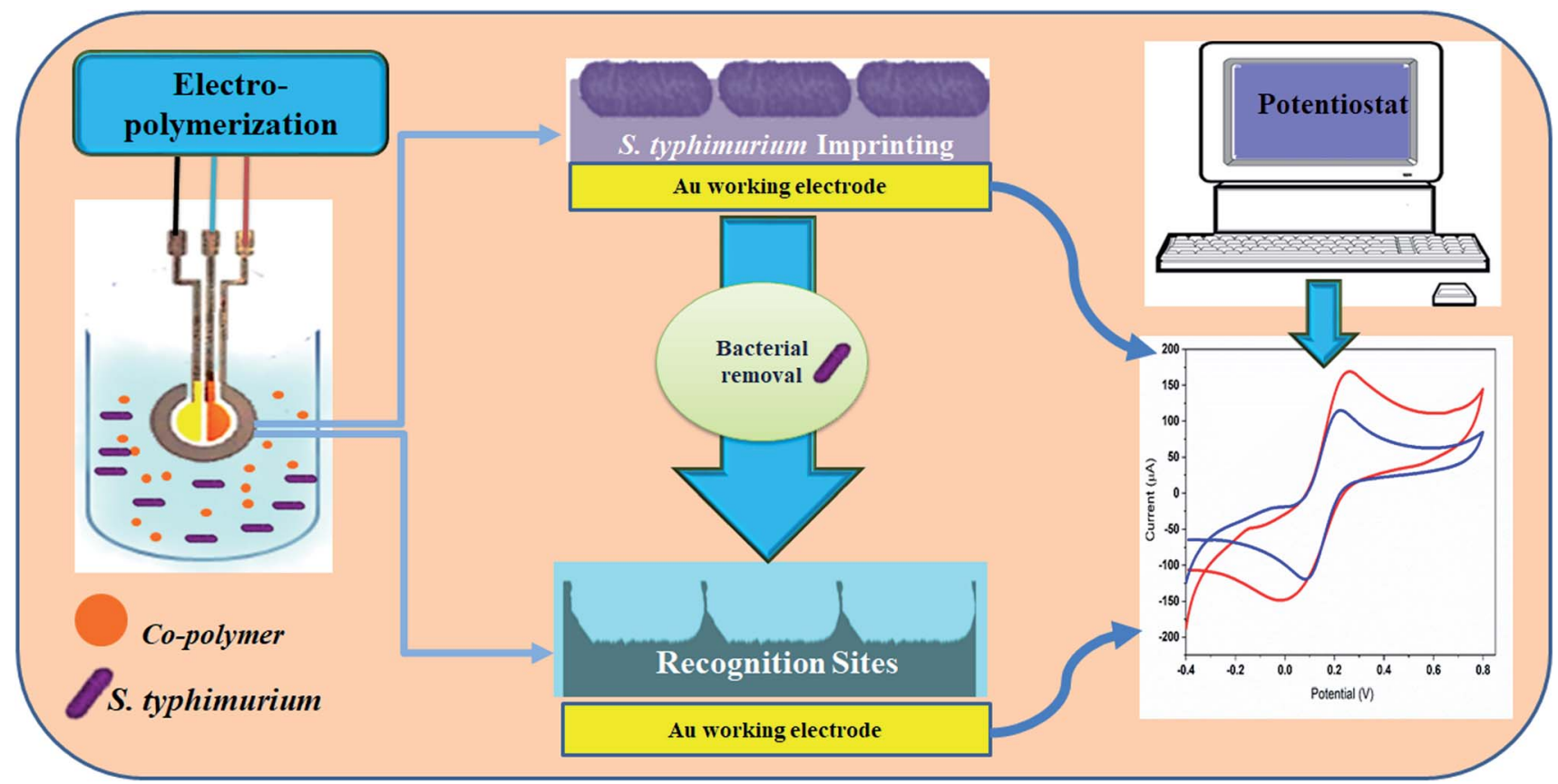

Fig. 1 A schematic diagram illustrating the main components and steps of the fabrication of the Salmonella-based-biosensor.
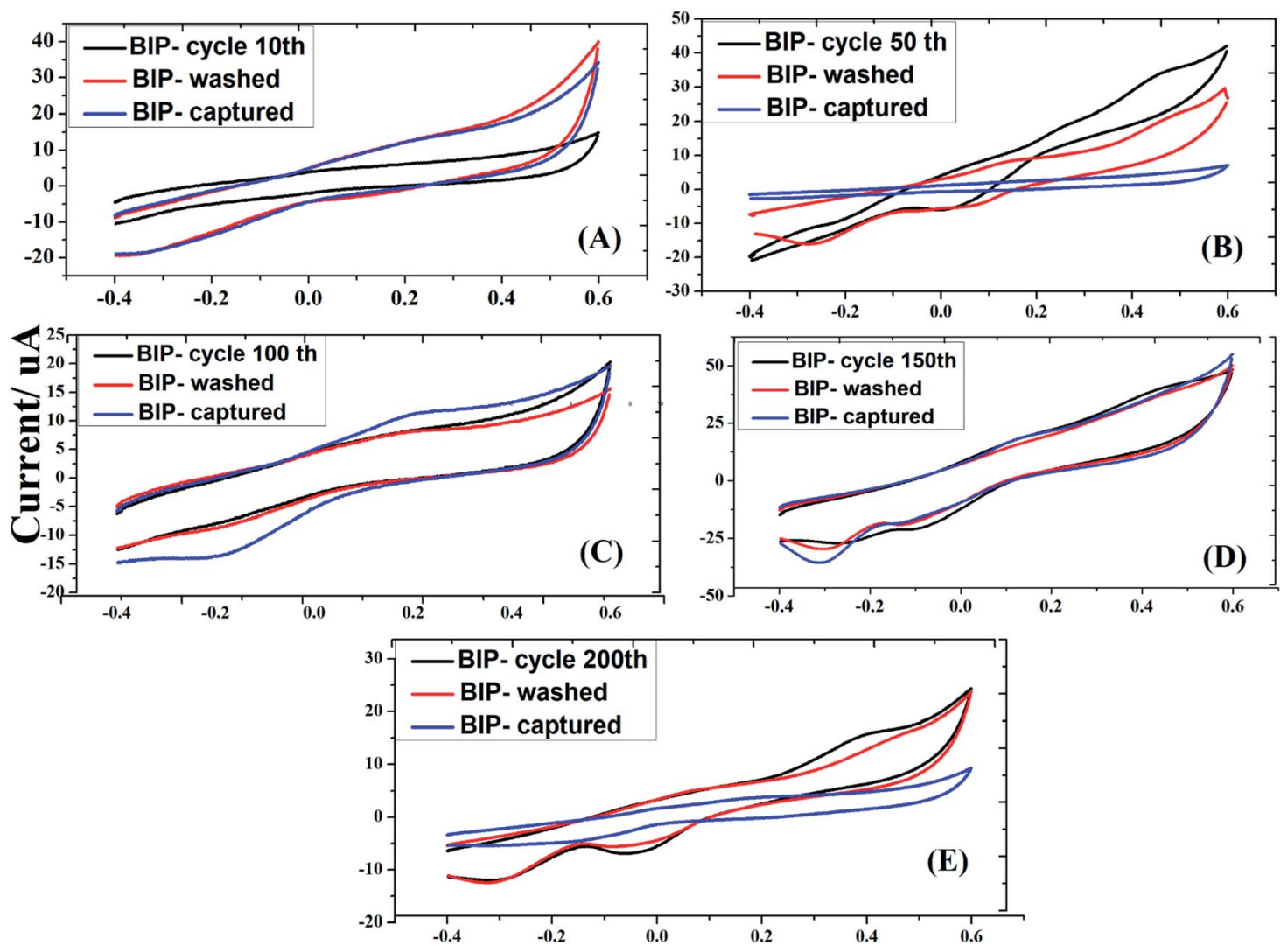

E/V

Fig. 2 Testing the effect of different numbers of cycles on the efficiency of BIPs towards the selective capturing of S. typhimurium. Each cycle was measured before washing (before removing the bacteria from the surface), and after washing (showing the electrochemical changes due to the evacuation of bacterial sites), and after rebinding the bacteria to the evacuated sites. 

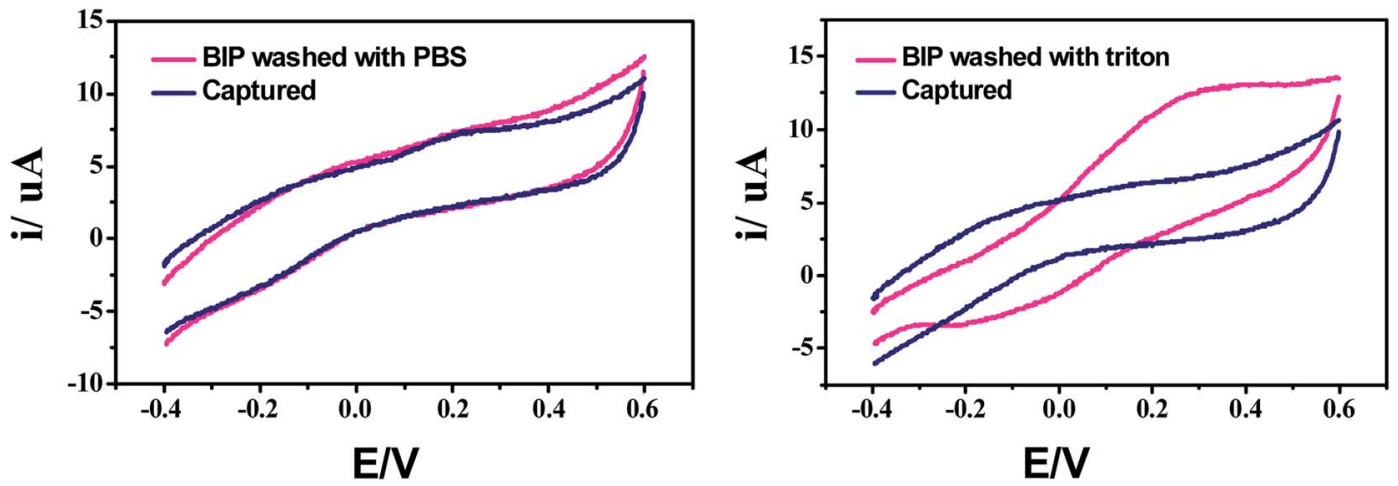

Fig. 3 Effect of bacterial removal using Triton (Triton X-100, 1\% in aqueous solution) or PBS for creating specific binding sites.

templates), which will be applied for its specific recognition (rebinding). Cyclic voltammetry will be exploited for performing the electro-polymerization as well as for measuring the rebinding responses to indicate the sensors performance. The selective binding to the created templates will lead to a decrease in the voltammetric signal (this concept is visualized in Fig. 1). The decrease in the voltammetric signals is relying on the selective capturing of the targeted bacterial cells, as well as on their concentration. Thus, the investigated faradaic currents will be gradually inhibited/decreased in response to the number of bound cells.
Coming back to the experiments, self-polymerization of dopamine could be carried out spontaneously under acidic or alkaline conditions, leading to the formation of polydopamine (PDA). ${ }^{29} \mathrm{PDA}$ is a biopolymer with high biocompatibility and low cytotoxicity. On the other hand, electrochemical polymerization of dopamine on the surface of a working electrode was conducted for achieving high effective surface functionalization. The electro-polymerization could be applied for controlling the thickness of the deposited layer of electro-polymerized dopamine through managing the number of voltammetric cycles and the speed of the scan rate..$^{30}$
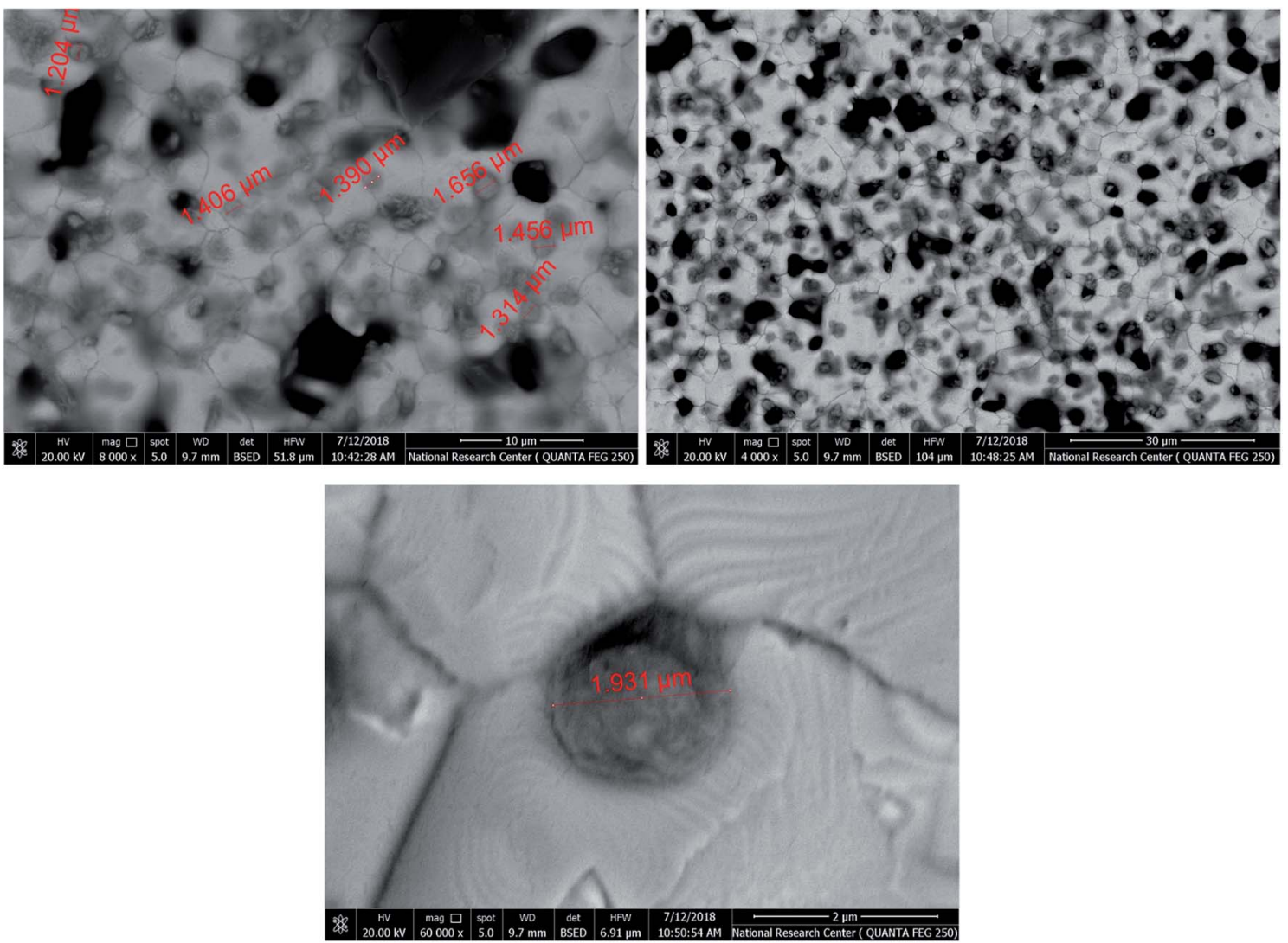

Fig. 4 SEM images of the various electrodes bound S. typhimurium on the imprinted electrodes with a bacteria concentration of $1 \times 10^{7} \mathrm{CFU}$ $\mathrm{ml}^{-1}$. S. typhimurium captured in poly-dopamine imprinted matrix (left side), the created cavities after removing bacterial cells (right side). 


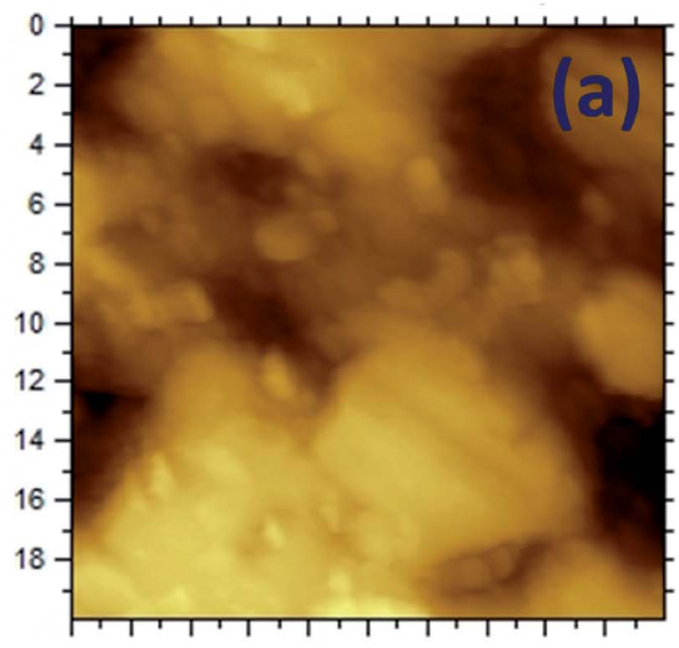

$\mu \mathrm{m}$

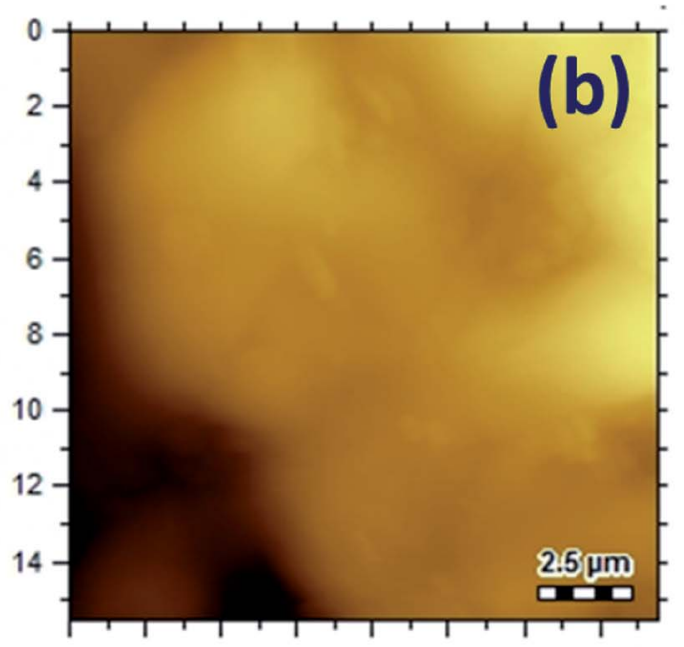

um
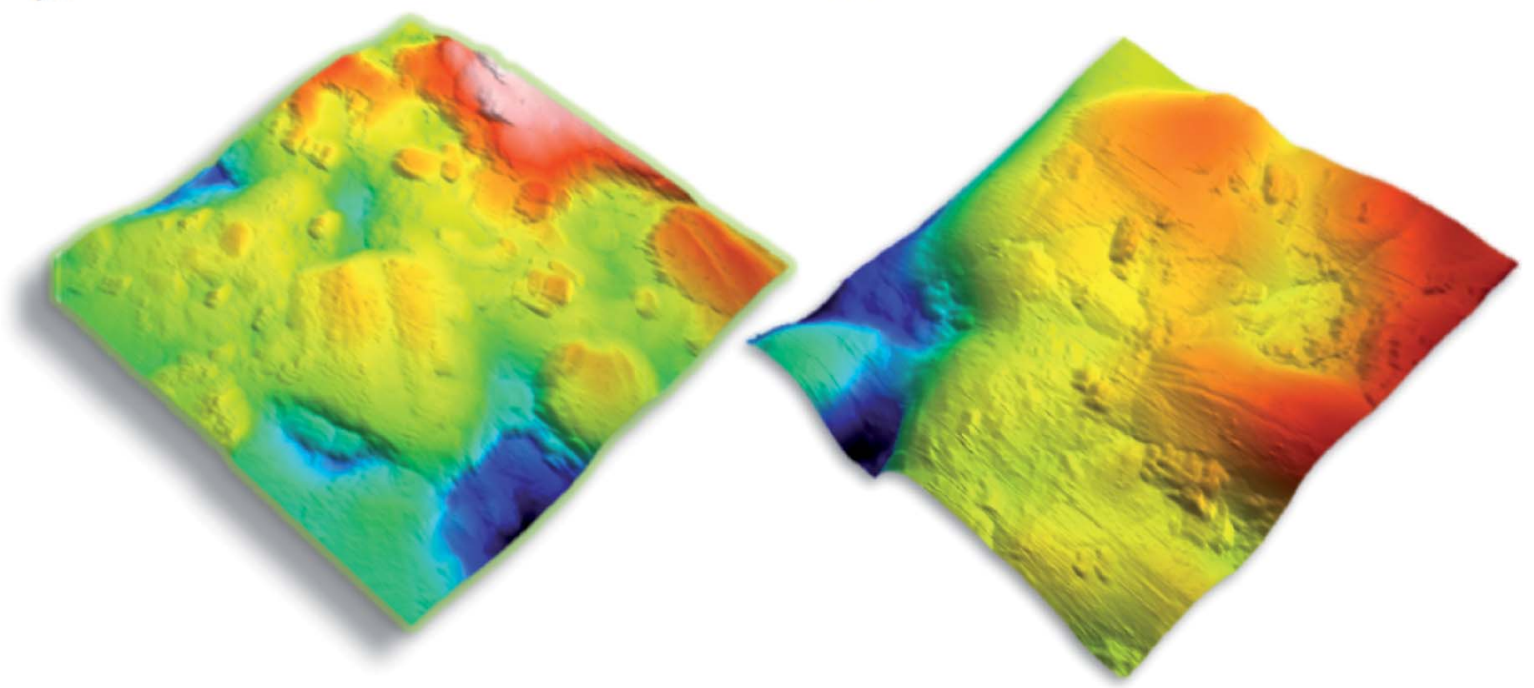

Fig. 5 AFM images of S. typhimurium imprinted in the electro-polymerized dopamine, the created cavities after removing bacterial cells from the BIP matrix.

In this work, electro-polymerization of dopamine was carried out in acetate buffer to include the imprinting the S. typhimurium on the surface of gold screen printed electrodes. In principle, multiple voltammetric cycles (10, 50, 100, 150 and $200 \mathrm{CVs})$ were investigated for the formation of effective bacterial imprinted polymer (BIP) biosensor. In this regard, Salmonella cells were imprinted and the impact of voltammetric cycles was evaluated from the rebinding responses of each imprinted surface. As a result, the highest efficiency of sensing was achieved when $50 \mathrm{CVs}$ were applied for forming the BIP. Exceeding the number of voltammetric cycling than 50 led to a decrease in the sensing performance, as shown in Fig. 2, due to increase in the formed polydopamine film thickness which might be hindering the efficient removal of entrapped bacteria from the active electrode surface.

\subsection{Removal of S. typhimurium particles from the imprinted matrix}

To create specific binding sites for selective biosensing of $S$. typhimurium, the BIP chips were incubated with Triton X-100
(1\% aqueous solution) or with PBS for $5 \mathrm{~min}$. The use of Triton as a removing agent exhibited higher performance towards creating more cavities (specific binding sites). This was clear from the obtained electrochemical signals, as shown in Fig. 3. On the other hand, the topographic changes in the BIP surfaces were analyzed by the scanning electron microscopy (SEM) and the atomic force microscopy (AFM). The SEM and the AFM images of the BIPs, before washing with Triton, showed the accumulation of particles with the average size $(2.0-5.0 \mu \mathrm{m})$. The vacant places equivalent to those sizes were observed on the BIP surfaces after washing, as shown in Fig. 4 and 5. From the imaging analysis, the successful imprinting of the S. typhimurium along with creating of recognition sites are confirmed.

\subsection{Evaluating the capturing efficiency of the sensor}

At different concentrations of S. typhimurium $\left(10^{5}, 10^{6}, 10^{7}\right.$, and $10^{9} \mathrm{CFU} \mathrm{ml}{ }^{-1}$ ), the capturing efficiency of washed BIPs was evaluated and their corresponding electrochemical responses were compared with the signals obtained from both the bare 

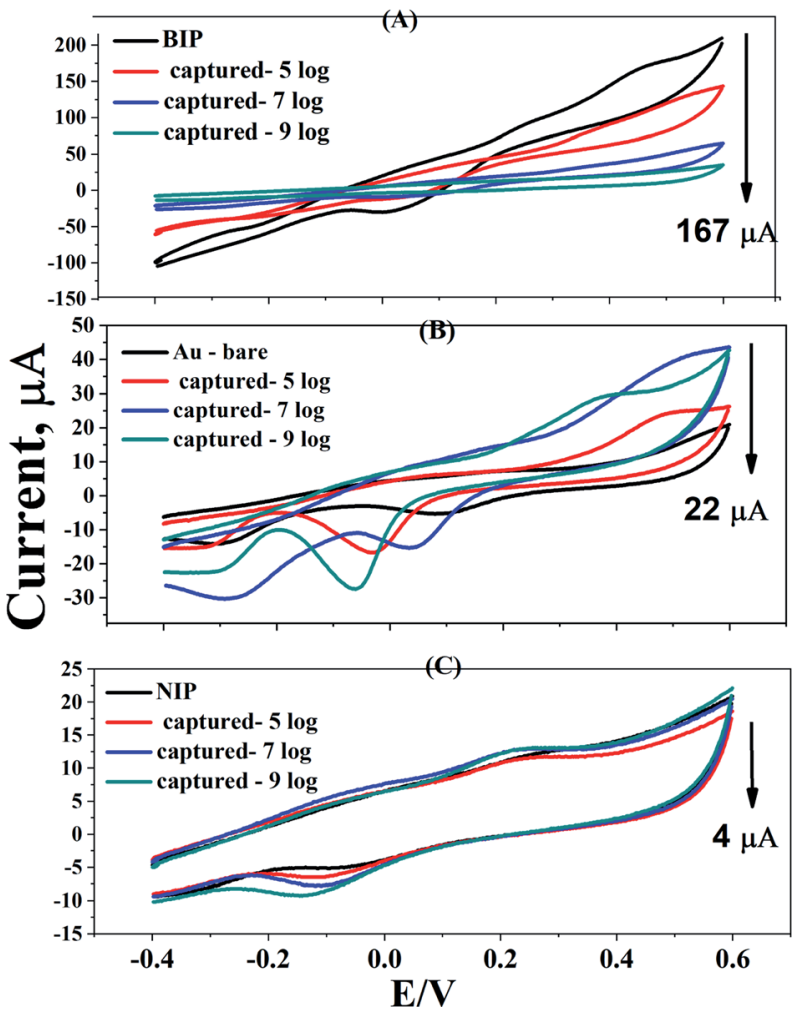

Fig. 6 Capturing efficiency of BIPs, NIPs and bare gold electrodes at different concentrations of $S$. typhimurium $\left(10^{5}, 10^{7}\right.$, and $10^{9}, \mathrm{CFU}$ $\mathrm{ml}^{-1}$ ). gold and the NIP-surfaces (no templates, and the electrodes are only loaded with electro-polymerized dopamine, respectively). A huge difference in faradaic current (about $200 \mu \mathrm{A}$ ) was obtained as a result of binding the bacterial cells to the BIP surface. While, less than $30 \mu \mathrm{A}$ was obtained by the non-selective attachment of the bacterial cells to the Au-bare-electrode or with the NIP surfaces. This result confirmed the high selectivity of the designed BIP to sense the S. typhimurium due to the imprinted, and well-designed bacterial templates, as shown in Fig. 6.

\subsection{Optimization of the sensor's response time}

To determine the appropriate sensing time for bacterial capturing, BIPs were incubated with cell suspension of $S$. typhimurium for different incubation periods (10 second, 1.0 min, 5.0 min and 10.0 min). As depicted in Fig. 7, equilibrium capturing was reached after $1.0 \mathrm{~min}$, followed by a decrease in the electrochemical signals at 5.0 and $10.0 \mathrm{~min}$. Therefore, $1.0 \mathrm{~min}$ was assigned as the ideal sensing and capturing time.

\subsection{Selectivity of the developed Salmonnela's biosensor}

In terms of specificity of the developed BIP towards $S$. typhimurium (the target strain), the biosensor was tested against nontargeted bacterial strains. Both of gram positive such as Staphylococcus aureus and Listeria monocytogenes, and gram negative
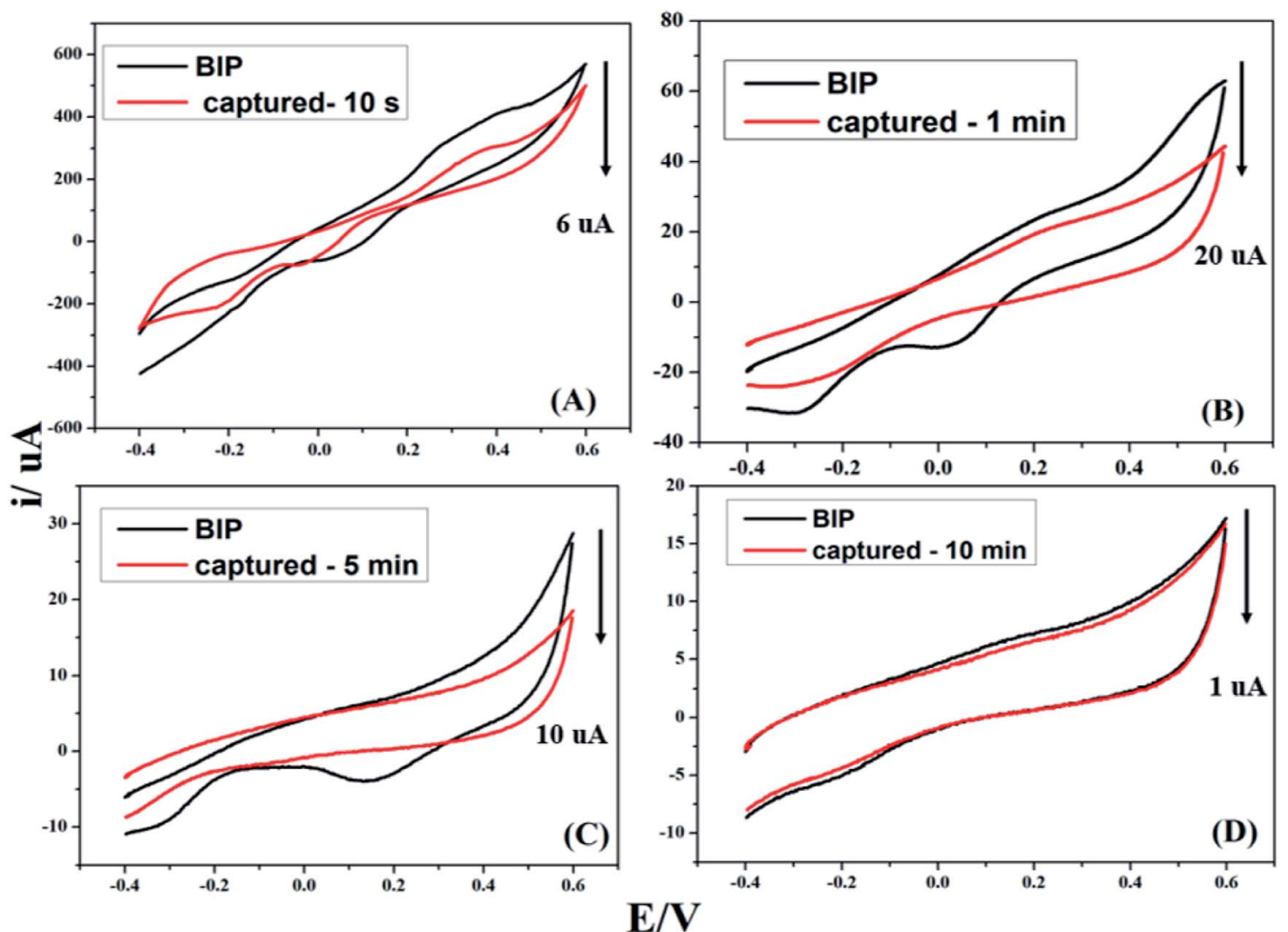

Fig. 7 Effect of interaction times (capturing time) on the bioelectrochemical signals of BIPs. 


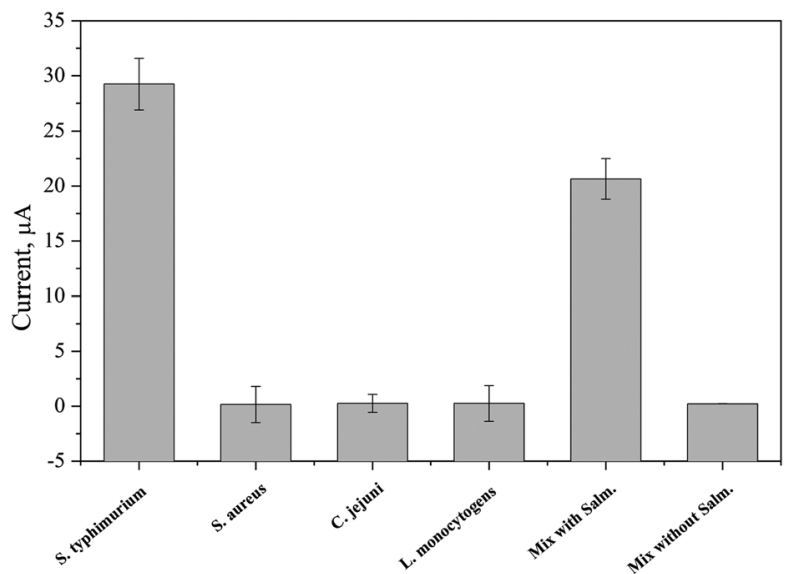

Fig. 8 Testing the selectivity of the biosensor for capturing the $S$. typhimurium from a pure and mixed cultures.

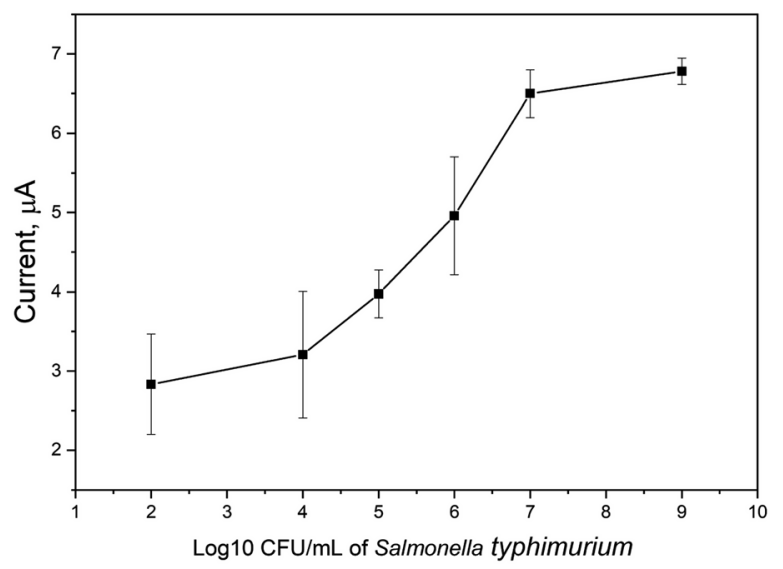

Fig. 9 Testing the sensors performance towards different concentrations of $S$. typhimurium. The measurements were performed in PBS $(\mathrm{pH} 7.4)$ and binding time is $1 \mathrm{~min}$.

such as Campylobacter jejuni were included. Equal concentrations of all bacterial strains $\left(10^{7} \mathrm{CFU} \mathrm{ml}{ }^{-1}\right)$, either as an individual (single) or in a mixed culture, were prepared for the electrochemical detection. The results given in Fig. 8 indicated the high specificity of the designed biosensor towards $S$. typhimurium and that there was no cross-reactivity neither in the single nor in the mixed bacterial culture. Hence, the developed biosensor is capable of distinguishing the $S$. typhimurium even in the presence of other microbial species.

\subsection{Calibration curve}

The sensitivity, and linear responses of the biosensor was determined by direct detection of different concentrations of Salmonella (cell concentration was ranged from $10^{2}$ to $10^{9} \mathrm{CFU}$ $\mathrm{ml}^{-1}$ ) at a capturing time of $1 \mathrm{~min}$. As shown in Fig. 9, a remarkable electrochemical signal was obtained even at the lowest cell count $\left(10^{2} \mathrm{CFU} \mathrm{ml}{ }^{-1}\right)$ with a strong correlation between the generated electrochemical signals and the increase of the bacterial cell number. Statistically, the limit of detection (LOD) of the biosensor was determined to be $47 \mathrm{CFU}$ $\mathrm{ml}^{-1}$, while the limit of quantification (LOQ) was $142 \mathrm{CFU}$ $\mathrm{ml}^{-1}$. Thus, the biosensor is able to quantify the concentration of Salmonella with high sensitivity, and statistical difference ( $p$ $=<0.0001$ ). Table 1 summarized the most recently reported biosensors for the detection of S. typhimurium, and the present BIP biosensor is among the most sensitive ones with high selectivity, short time of analysis, and without microbiological complications.

\subsection{Biosensor application in meat samples}

After reaching the optimal conditions, the biosensor was exploited for the detection of $S$. typhimurium in a complex matrix of artificially contaminated minced beef samples. Here, the beef samples were synthetically contaminated with two bacterial concentrations $\left(10^{2}\right.$ and $\left.10^{4} \mathrm{CFU} \mathrm{ml}{ }^{-1}\right)$, and the biosensors responses were obtained (as shown in Fig. 10). The recovery was very high, and plating method was used as a reference for validation.

\section{Conclusion}

For rapid detection of food contamination, electropolymerization of $S$. typhimurium on screen printed electrodes was carried out through the voltammetric imprinting of polydopamine layer. Effective removal of the imprinted bacterial

Table 1 Comparison of the response of previously reported biosensors for the detection of $S$. typhimurium

\begin{tabular}{llll}
\hline Electrochemical technique & $\begin{array}{l}\text { Detection time } \\
(\mathrm{min})\end{array}$ & LOD $\left(\mathrm{CFU} \mathrm{ml}{ }^{-1}\right)$ & Real sample analysis \\
\hline Differential pulse voltammetry (DPV) & 90 & $1.5 \times 10^{5}$ & Milk \\
Cyclic voltammetric & 80 & 3000 & Eggs and chicken meat \\
Amperometric & 60 & 291 & Milk \\
Amperometric & 30 & 60 & Chicken meat \\
Impedimetric & 90 & 10 & Pork meat \\
Impedimetric & 30 & 150 & Milk \\
Immunoelectrochemical method & 120 & 1000 & Chicken carcass \\
Immunosensor & 120 & 10 & Chicken meat \\
Electrochemiluminescence & 30 & 10 & Beef \\
Cyclic voltammetric & 10 & 47 & Ground beef meat
\end{tabular}




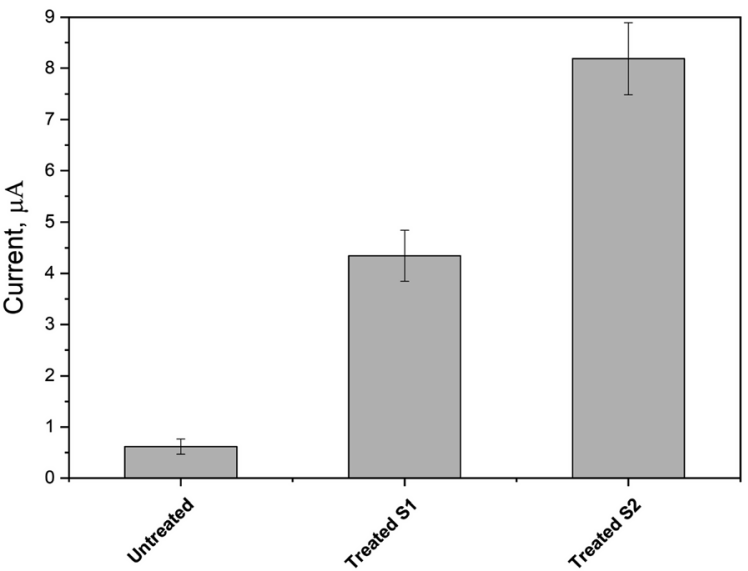

Fig. 10 Detection of S. typhimurium in artificially minced beef meat samples using the proposed sensor. Three meat samples were used (labeled untreated (no Salmonella contamination), treated S1 (Salmonella contaminated sample-1 with $2 \log \left(F U \mathrm{~mL}^{-1}\right)$, and treated S2 (Salmonella contaminated sample-2 with $4 \log \mathrm{CFUmL}{ }^{-1}$ ).

cells from the polymeric substrate created the specific binding sites. Accordingly, the biosensing assay was fully optimized and the biosensor was successfully applied for tracking the $S$. typhimurium contamination in beef samples. With one minute as the total capturing time, the proposed biosensor is considered as a rapid, sensitive, and selective towards the bacterial target determination in food, and complex samples.

\section{Author contributions}

S. A. K. performed the microbiological experiments. R. Y. A. H. designed the biosensor, performed electrochemical measurements, visualized the obtained results, wrote and revised the manuscript. R. M. E., and I. M. E. supervised the project, revised, and submitted the manuscript. All authors have read and agreed to the published version of the manuscript.

\section{Conflicts of interest}

The authors declare no conflict of interest.

\section{References}

1 E. Yeleliere, S. J. Cobbina and Z. I. Abubakari, Review of microbial food contamination and food hygiene in selected capital cities of Ghana, Cogent Food Agric., 2017, 3(1), 1395102.

2 O. Grundmann, The current state of bioterrorist attack surveillance and preparedness in the US, Risk Manag Healthc Policy., 2014, 7, 177-187.

3 R. Dieckmann, R. Helmuth, M. Erhard and B. Malorny, Rapid classification and identification of salmonellae at the species and subspecies levels by whole-cell matrixassisted laser desorption ionization-time of flight mass spectrometry, Appl. Environ. Microbiol., 2008, 74(24), 77677778.
4 S.-K. Eng, P. Pusparajah, N.-S. Ab Mutalib, H.-L. Ser, K.-G. Chan and L.-H. Lee, Salmonella: A review on pathogenesis, epidemiology and antibiotic resistance, Front. Life Sci., 2015, 8(3), 284-293.

5 E. N. Takem, A. Roca and A. Cunnington, The association between malaria and non-typhoid Salmonella bacteraemia in children in sub-Saharan Africa: a literature review, Malar. J., 2014, 13, 400.

6 H. J. Chun, S. Kim, Y. D. Han, K. R. Kim, J. H. Kim, H. Yoon and H. C. Yoon, Salmonella typhimurium Sensing Strategy Based on the Loop-Mediated Isothermal Amplification Using Retroreflective Janus Particle as a Nonspectroscopic Signaling Probe, ACS Sens., 2018, 3(11), 2261-2268.

7 S. Wang, L. Zheng, G. Cai, N. Liu, M. Liao, Y. Li, X. Zhang and J. Lin, A microfluidic biosensor for online and sensitive detection of Salmonella typhimurium using fluorescence labeling and smartphone video processing, Biosens. Bioelectron., 2019, 140, 111333.

8 L. Váradi, J. L. Luo, D. E. Hibbs, J. D. Perry, R. J. Anderson, S. Orenga and P. W. Groundwater, Methods for the detection and identification of pathogenic bacteria: past, present, and future, Chem. Soc. Rev., 2017, 46(16), 4818-4832.

9 D. R. Call, M. K. Borucki and F. J. Loge, Detection of bacterial pathogens in environmental samples using DNA microarrays, J. Microbiol. Methods, 2003, 53(2), 235-243.

10 K. H. Jensen, R. Dargis, J. J. Christensen and M. Kemp, Ribosomal PCR and DNA sequencing for detection and identification of bacteria: experience from 6 years of routine analyses of patient samples, APMIS, 2014, 122(3), 248-255.

11 M. N. Souza, F. K. M. Lehmann, S. De Carli, D. Kipper, A. S. K. Fonseca, N. Ikuta and V. R. Lunge, Molecular detection of Salmonella serovars Enteritidis, Heidelberg and typhimurium directly from pre-enriched poultry samples, Br. Poult. Sci., 2019, 60(4), 388-394.

12 J. Hu, R. Huang, Y. Sun, X. Wei, Y. Wang, C. Jiang, Y. Geng, X. Sun, J. Jing, H. Gao, Z. Wang and C. Dong, Sensitive and rapid visual detection of Salmonella typhimurium in milk based on recombinase polymerase amplification with lateral flow dipsticks, J. Microbiol. Methods, 2019, 158, 25-32.

13 M. Kemp, K. H. Jensen, R. Dargis and J. J. Christensen, Routine ribosomal PCR and DNA sequencing for detection and identification of bacteria, Future Microbiol., 2010, 5(7), 1101-1107.

14 F. Mustafa, R. Y. A. Hassan and S. Andreescu, Multifunctional Nanotechnology-Enabled Sensors for Rapid Capture and Detection of Pathogens, Sensors, 2017, 17(9), 2121.

15 H. M. M. Selim, A. M. Kamal, D. M. M. Ali and R. Y. A. Hassan, Bioelectrochemical Systems for Measuring Microbial Cellular Functions, Electroanalysis, 2017, 29(6), 1498-1505.

16 R. Y. A. Hassan and U. Wollenberger, Direct Determination of Bacterial Cell Viability Using Carbon Nanotubes Modified Screen-printed Electrodes, Electroanalysis, 2019, 31(6), 1112-1117. 
17 M. Sedki, R. Y. A. Hassan, A. Hefnawy and I. M. El-Sherbiny, Sensing of bacterial cell viability using nanostructured bioelectrochemical system: rGO-hyperbranched chitosan nanocomposite as a novel microbial sensor platform, Sens. Actuators, B, 2017, 252, 191-200.

18 H. S. Magar, R. Y. A. Hassan and A. Mulchandani, Electrochemical Impedance Spectroscopy (EIS): Principles, Construction, and Biosensing Applications, Sensors, 2021, 21(19), 6578.

19 P. Poltronieri, V. Mezzolla, E. Primiceri and G. Maruccio, Biosensors for the Detection of Food Pathogens, Foods, 2014, 3(3), 511-526.

20 J. Fei, W. Dou and G. Zhao, A sandwich electrochemical immunoassay for Salmonella pullorum and Salmonella gallinarum based on a AuNPs/SiO2/Fe3O4 adsorbing antibody and 4 channel screen printed carbon electrode electrodeposited gold nanoparticles, RSC Adv., 2015, 5(91), 74548-74556.

21 R. Mutreja, M. Jariyal, P. Pathania, A. Sharma, D. K. Sahoo and C. R. Suri, Novel surface antigen based impedimetric immunosensor for detection of Salmonella typhimurium in water and juice samples, Biosens. Bioelectron., 2016, 85, 707-713.

22 E. Sheikhzadeh, M. Chamsaz, A. P. F. Turner, E. W. H. Jager and V. Beni, Label-free impedimetric biosensor for salmonella typhimurium detection based on poly [pyrroleco-3-carboxyl-pyrrole] copolymer supported aptamer, Biosens. Bioelectron., 2016, 80, 194-200.

23 E. Roy, S. Patra, A. Tiwari, R. Madhuri and P. K. Sharma, Retraction notice to Single cell imprinting on the surface of Ag-ZnO bimetallic nanoparticle modified graphene oxide sheets for targeted detection, removal and photothermal killing of E. coli Biosensors and Bioelectronics volume 89, part 1, 15 march 2017, pages 620-626, Biosens. Bioelectron., 2018, 112, 216.

24 H. A. Hussein, R. Y. A. Hassan, R. M. El Nashar, S. A. Khalil, S. A. Salem and I. M. El-Sherbiny, Designing and fabrication of new VIP biosensor for the rapid and selective detection of foot-and-mouth disease virus (FMDV), Biosens. Bioelectron., 2019, 141, 111467.

25 M.-H. Lee, J. L. Thomas, W.-J. Chen, M.-H. Li, C.-P. Shih and H.-Y. Lin, Fabrication of Bacteria-imprinted Polymer Coated Electrodes for Microbial Fuel Cells, ACS Sustainable Chem. Eng., 2015, 3(6), 1190-1196.

26 R. Schirhagl, Bioapplications for molecularly imprinted polymers, Anal. Chem., 2014, 86(1), 250-261.

27 T. Cohen, J. Starosvetsky, U. Cheruti and R. Armon, Whole cell imprinting in sol-gel thin films for bacterial recognition in liquids: macromolecular fingerprinting, Int. J. Mol. Sci., 2010, 11(4), 1236-1252.

28 H. A. Hussein, A. Kandeil, M. Gomaa, R. Mohamed El Nashar, I. M. El-Sherbiny and R. Y. A. Hassan, SARS-CoV-2-
Impedimetric Biosensor: Virus-Imprinted Chips for Early and Rapid Diagnosis, ACS Sens., 2021, 6(11), 4098-4107.

29 J.-l. Wang, B.-c. Li, Z.-j. Li, K.-f. Ren, L.-j. Jin, S.-m. Zhang, H. Chang, Y.-x. Sun and J. Ji, Electropolymerization of dopamine for surface modification of complex-shaped cardiovascular stents, Biomaterials, 2014, 35(27), 76797689.

30 J. L. Wang, B. C. Li, Z. J. Li, K. F. Ren, L. J. Jin, S. M. Zhang, H. Chang, Y. X. Sun and J. Ji, Electropolymerization of dopamine for surface modification of complex-shaped cardiovascular stents, Biomaterials, 2014, 35(27), 7679-7689.

31 A. S. Afonso, B. Pérez-López, R. C. Faria, L. H. C. Mattoso, M. Hernández-Herrero, A. X. Roig-Sagués, M. Maltez-da Costa and A. Merkoçi, Electrochemical detection of Salmonella using gold nanoparticles, Biosens. Bioelectron., 2013, 40(1), 121-126.

32 J. Fei, W. Dou and G. Zhao, A sandwich electrochemical immunosensor for Salmonella pullorum and Salmonella gallinarum based on a screen-printed carbon electrode modified with an ionic liquid and electrodeposited gold nanoparticles, Microchim. Acta, 2015, 182(13), 2267-2275.

33 D. Brandão, S. Liébana, S. Campoy, S. Alegret and M. Isabel Pividori, Immunomagnetic separation of Salmonella with tailored magnetic micro and nanocarriers. A comparative study, Talanta, 2015, 143, 198-204.

34 S. Cinti, G. Volpe, S. Piermarini, E. Delibato and G. Palleschi, Electrochemical Biosensors for Rapid Detection of Foodborne Salmonella: A Critical Overview, Sensors, 2017, 17(8), 1910.

35 L. Yang, C. Ruan and Y. Li, Detection of viable Salmonella typhimurium by impedance measurement of electrode capacitance and medium resistance, Biosens. Bioelectron., 2003, 19(5), 495-502.

36 F. Malvano, R. Pilloton and D. Albanese, A novel impedimetric biosensor based on the antimicrobial activity of the peptide Nisin for the detection of Salmonella spp, Food Chem., 2020, 325, 126868.

37 Y. H. Che, Y. Li, M. Slavik and D. Paul, Rapid detection of Salmonella typhimurium in chicken carcass wash water using an immunoelectrochemical method, J. Food Prot., 2000, 63(8), 1043-1048.

38 A. Fulgione, M. Cimafonte, B. Della Ventura, M. Iannaccone, C. Ambrosino, F. Capuano, Y. T. R. Proroga, R. Velotta and R. Capparelli, QCM-based immunosensor for rapid detection of Salmonella typhimurium in food, Sci. Rep., 2018, 8(1), 16137.

39 Y. Luo, F. Lv, M. Wang, L. Lu, Y. Liu and X. Xiong, A multicolor electrochemiluminescence device based on closed bipolar electrode for rapid visual screening of Salmonella typhimurium, Sens. Actuators, B, 2021, 349, 130761. 